\title{
The Importance of Social Contextual Factors in Peer Relationships of Children with ADHD
}

\author{
Amori Yee Mikami • Sébastien Normand
}

Published online: 7 January 2015

(C) Springer International Publishing Switzerland 2015

\begin{abstract}
Children with Attention Deficit/Hyperactivity Disorder (ADHD) often have poor peer relationships, as evidenced by difficulties in being accepted and befriended by peers, as well as poor quality and stability in any friendships they do have. This peer impairment is important for researchers and clinicians to consider because it can exacerbate behavior problems, emotional maladjustment, and academic failure over time in children with ADHD. In this review, we highlight the important ways in which children with ADHD demonstrate impairment in their peer relationships. We argue that the traditional conceptualization of peer problems, which focuses on inappropriate behaviors within children with ADHD to explain their social difficulties, fails to take into account peer group factors that also contribute to the peer impairment seen in ADHD populations. Further, the predominant focus on changing the behavior deficits of children with ADHD has limited the design of effective treatments that address the multifaceted reasons for peer impairment in this population. We conclude with a discussion of implications and future directions for clinical intervention and research.
\end{abstract}

Keywords ADHD · Peer relationships · Friendships · Social behavior $\cdot$ Interventions

This article is part of the Topical Collection on $A D H D$

A. Y. Mikami $(\bowtie)$

Department of Psychology, University of British Columbia, 2136

West Mall, Vancouver, BC V6T 1Z4, Canada

e-mail: mikami@psych.ubc.ca

\section{S. Normand}

Department of Psychology, Université du Québec en Outaouais and Montfort Hospital Research Institute, 283 Alexandre Taché Blvd., Hull station, P.O. BOX 1250, Gatineau, QC J8X 3X7, Canada

e-mail: sebastien.normand@uqo.ca

\section{Introduction}

Although social problems are not part of the diagnostic criteria for Attention Deficit/Hyperactivity Disorder (ADHD) [1], impairment in peer relationships is a prominent associated feature of this condition [2,3]. Peer impairment can be displayed in multiple ways $[4,5]$, but common manifestations include children's high rejection and low acceptance in their peer group, and their tendency to have fewer, or no, reciprocated friendships [3]. In this review, we first describe the magnitude of the peer problems faced by children with ADHD, as well as the potential impact of these peer difficulties on children's subsequent behavioral, emotional, and academic maladjustment. We then discuss the predominant conceptualization of why these peer problems occur, which focuses on the inappropriate behaviors displayed by children with ADHD. Crucially, we argue why this conceptualization is incomplete, and suggest a broader perspective that accounts the contribution of the peer group to the poor social functioning of children with ADHD. We conclude with suggestions for future research and interventions based on this broader conceptualization that may be beneficial for ameliorating peer relationship problems among children with ADHD.

\section{Peer Problems Among Children with ADHD}

The impairment in peer relationships faced by children with ADHD is difficult to overstate. Interestingly, their peer impairment likely exceeds that demonstrated by children with other psychiatric conditions such as depression, anxiety, learning problems, or conduct problems in the absence of ADHD $[6,7]$. One meta-analysis reported the effect size of peer problems relative to typically developing youth as $d=.72$ for children with ADHD and no comorbidities to $d=1.25$ for children with ADHD and comorbid conduct problems [8], which are considered to be medium to large effects [9]. 
Further, elevated ADHD symptoms are associated with peer impairment among children in general education classrooms who do not necessarily meet formal criteria for the disorder [10-12].

Researchers have found that children with ADHD are approximately four times more likely to be rejected by their peers relative to typical children [3], even after periods of social contact as brief as a few hours $[13,14]$. That is, using sociometric nomination methods where peers are asked to name classmates whom they like most and least, children with ADHD receive many "like least" nominations and few "like most" nominations from classmates [3, 15]. Other investigations have found that $52-82 \%$ of children with ADHD score greater than 1 standard deviation above their classroom mean in peer rejection $[3,16]$.

In addition to being rejected by peers, children with ADHD demonstrate impairment in their friendships [17]. Friendship is a voluntary bond co-created by two individuals who expect to share safe, intimate, and rewarding experiences with mutual commitment, support, and validation of each other. Although peer acceptance and having friends tend to be correlated, it is possible for a child to be disliked by many (or most) peers and still have one or more good friends [18]. Nonetheless, research suggests that boys and girls with ADHD are nearly twice as likely as typically developing youth to have no friends in their classroom $[3,19]$. In fact, one study found that fully $76 \%$ of children with ADHD and comorbid conduct problems did not have a single reciprocated friend in their class [7].

In addition to having a smaller number of friends, a further concern is poorer relationship quality (e.g., conflict, lack of closeness), as well as lack of stability, and the tendency to have friends with more behavior problems themselves, in any friendships children with ADHD do have [19, 20, 21 •, 22, 23]. The few observational studies of interactions between children with ADHD and their friends suggest that children with ADHD tend to be less sensitive to their friends' needs and preferences, instead acting based on their own interests and attempting to control the play [20]. These same behavioral tendencies were found to predict prospectively a deterioration in friendship quality over time for children with ADHD, a pattern in marked contrast to that observed in the friendships of typically developing children [21•].

\section{Implications of Peer Problems for Maladjustment}

Peer problems are concerning because they incrementally increase the likelihood that children with ADHD will experience subsequent behavioral and emotional maladjustment. Results from several investigations suggest that if children with ADHD are rejected by peers, this augments the risk associated with ADHD diagnostic status for depression, anxiety, delinquency, academic failure, eating pathology, and substance abuse in adolescence [24-26]. Recent evidence finds that, in addition to ADHD symptoms predicting peer problems, peer rejection may actually exacerbate ADHD symptoms over the course of a year [27॰]. Being disliked by peers may compound adjustment problems, leading to cascading negative effects of peer problems over time. For instance, in one study, children's peer rejection predicted their poorer social skills 1 to 3 years later, which in turn predicted exacerbated peer rejection and poor emotional adjustment 6 years later in adolescence [28].

The prospective link between peer rejection and subsequent academic problems is particularly robust. Such associations exist after statistical control of the original childhood levels of academic achievement [29]. For example, one study found that peer rejection and ADHD diagnostic status made independent contributions to academic achievement 5 years later, after statistical control of the baseline levels of achievement and IQ scores [24]. In another study, observations of peer victimization during class time predicted restricted growth within one academic year on students' state-based standardized reading achievement test scores, after statistical control of their previous reading achievement test scores, ADHD symptom severity, and ability grouping (i.e., tracking) in their classroom [30]. It is thought that peer problems incrementally contribute to emotional and behavioral maladjustment by (a) increasing children's loneliness, which contributes to depression and anxiety [31]; (b) leading children to dislike school because they lack good social ties in that setting, which hampers academic learning [29] and encourages delinquency [32]; and (c) depriving children of valuable opportunities to develop or practice social skills [33].

Whereas findings have been relatively consistent in documenting the prospective relationships between peer rejection and subsequent maladjustment, results have been mixed for the effects of friendship on these outcomes. Some studies in samples of children with externalizing behavior or ADHD have found that having at least one good friend buffers the negative effects of peer rejection on maladjustment [34, 35] and receipt of victimization [36]. However, other work involving an ADHD sample found that only peer rejection, and not friendship, contributed to negative outcomes such as depression 6 and 8 years later [37]. The mixed results may be attributable to the fact that these studies have focused on the quantity of friends as a predictor, and have not considered friendship quality, stability, or the characteristics of the friends.

\section{Historical Conceptualizations of Peer Problems in ADHD}

To understand why children with ADHD experience difficulties in their peer relationships, researchers have predominantly, if not nearly exclusively, focused on the characteristics of children with ADHD that contribute to social rejection by their peers. For instance, there is a wealth of literature 
regarding the disruptive and offensive behaviors, lack of prosocial behaviors, and emotion regulation problems of children with ADHD that lead to peers' disliking [13, 15, 38, 39].

Space limitations permit only a brief review of this research here. In one observational study conducted with 259 previously unacquainted children attending summer camp, not following activity rules, complaining, whining, teasing, and inattention to others best predicted peer rejection in children with ADHD [40]. Although aggression is robustly (and very rapidly) linked to peer rejection among children with ADHD, social isolation and lack of prosocial behavior may also predict children being less liked and more disliked by their peers $[13,15]$. Moreover, a recent study with 172 children with ADHD found that poorer teacher-reported social self-control was associated with children's greater externalizing behavior, which was then linked to receiving fewer "like most" nominations from peers [38]. Other research suggests that social cognitive deficits such as poor perspective taking skills, reduced empathy, theory of mind problems, overestimation of one's own social competence, social information processing biases, and sensation seeking goals may also contribute to the peer problems of children with ADHD [41-45]. These findings are essential to understanding how problem behaviors and social skills deficits in children with ADHD lead to peer rejection.

Whereas this literature adds important information toward understanding the considerable peer impairment faced by children with ADHD, this framework neglects to examine the ways in which peers also contribute to these social problems. Peer relationships are inherently bidirectional, reflecting a back and forth process between children with ADHD and their peers; nonetheless, the focus of the current literature has remained largely on the rejected child with ADHD and rarely on the peers who are rejecting the child with ADHD [46]. To understand why peer rejection persists and how peer relationships can be improved for children with ADHD, further exploration into peers' contributions is imperative. The framework of focusing on the inappropriate social behaviors of children with ADHD to explain their peer impairment is not only apparent when reviewing the existing literature, but also reflected in the most commonly used interventions for peer problems among children with ADHD.

\section{Social Contextual Factors in Peer Problems}

Although we agree that disruptive behavior and lack of prosocial skills on the part of children with ADHD do contribute to their peer problems, we shift the existing paradigm by also addressing the contribution of the peer group (see Fig. 1). That is, inappropriate behaviors within children with ADHD are well-documented to be important contributors to their peer problems. However, we argue that the exclusive focus on behavior deficits as explaining the peer problems of

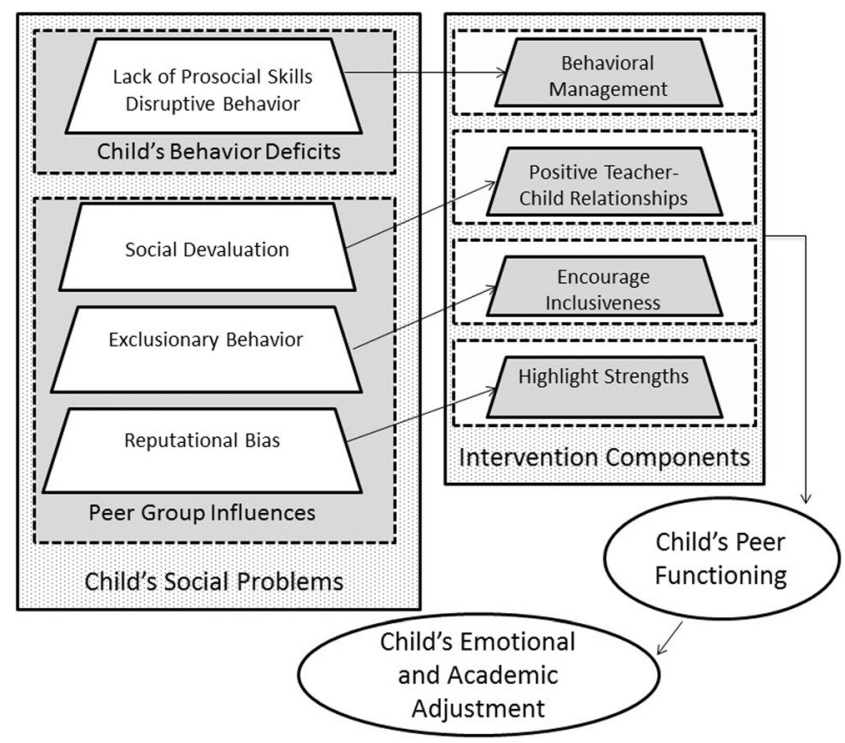

Fig. 1 Children's behavior deficits and peer group influences as contributors to social problems

children with ADHD is an incomplete conceptualization [46]. Below, we list three peer group influences that may contribute to peers' dislike (i.e., social devaluation, exclusionary behavior, and reputational bias), above and beyond the behavior deficits of disliked children. In each case, we explain why such peer group influences may be particularly relevant to explaining the social impairment of children with ADHD. However, we note that these same peer group factors may pertain to children who are disliked for reasons other than ADHD.

Social Devaluation. Peer problems experienced by children may be influenced, in part, by peers' stigmatizing attitudes toward disliked children. Research suggests that peers socially devalue classmates whom they perceive as dissimilar from themselves [47]; for this reason, children with internalizing problems are relatively better socially accepted in classrooms where there is more internalizing behavior present, whereas children with externalizing problems are relatively better accepted in classrooms where externalizing behavior is the peer group norm [48]. The point of this research is not to deny the contribution of children's own internalizing or externalizing behavior to their peer problems, but rather to emphasize that the extent to which peers have a culture that devalues certain behaviors also affects the severity and magnitude of peer impairment that a child with such inappropriate behavior is likely to experience. Indeed, peers will also socially devalue (and reject) classmates who are dissimilar from themselves for other reasons that do not relate to behavior problems, such as being of a different race or ethnicity [49].

Children with ADHD are a population for whom peers' social devaluation is likely to be especially severe. Relative to peers' automatic reactions toward children with physical 
health conditions, depression, and anxiety, peers possess the most negative automatic judgments about children displaying hyperactive/impulsive behaviors and most view these children as responsible for their actions [50]. Perceptions that children can control their problem behavior have been found to mediate the relationship between ADHD symptoms and peer rejection [51]. The label of ADHD may also evoke social devaluation beyond the specific behaviors associated with this disorder, as even when targets' behaviors are held constant, peers make more negative social judgments about targets whose behaviors have been labeled as "due to ADHD" as opposed to when such a label is not provided $[52,53]$.

Exclusionary Behavior. Being on the receiving end of peers' exclusionary behavior may also intensify peer problems. Peers can be cruel toward children whom they dislike; one study taking place in general education classrooms observed rejected children via wireless "bugging" and categorized 32 types of rejecting behaviors that peers enacted against these children such as saying mean things within earshot, preventing access to information or resources, spreading rumors/lies, taking or destroying possessions, in addition to overt physical aggression [54]. Being the recipient of exclusionary peer behavior can then exacerbate the disliked child's original levels of peer rejection, because such peer behavior broadcasts that the child is low status and discourages other children who might have included the child from doing so [30, 55].

Although the aforementioned studies have taken place using community samples, this process is likely especially relevant for children with ADHD. This is because the mere expectation that a child has ADHD may be sufficient to induce exclusionary peer behavior, above and beyond the actual inappropriate behaviors of that child. In a series of studies where child participants were either told or not told that a partner with whom they were about to interact had ADHD, observers rated the participants as less friendly and more hostile when participants expected the partner to have ADHD (even when the partner was in fact typically developing) [56, 57].

Reputational Bias. Once peers become inclined to view a child negatively, it is difficult to revise their impressions. Studies about the persistence of negative reputations find that peers interpret the ambiguous behaviors of children they dislike as hostile in intent, selectively remember their unskilled behavior, and make internal, global, and stable attributions for their poor behaviors [58]. Meanwhile, similar actions performed by well-liked children are perceived benignly [59, $60]$. Note that these studies have taken place using community samples, so this process is not specific to disliked children with ADHD.

Although peers may develop negative impressions of a child because that child has behaved badly, an implication is that even if a child with ADHD improves his or her behavior, the peer group may process that child's actions in a way that leads them to maintain their negative views. Thus, even if interventions produce improvements in the inappropriate behaviors of a child with ADHD, these interventions have not produced the changes in the peer group's cognitive biases that may be necessary for peers' acceptance and friendship.

Implications of the Social Contextual Model for Interventions

Existing treatments for ADHD typically involve a combination of psychosocial behavioral management and medication. Whereas these approaches are intended to reduce ADHD symptoms broadly, it is thought that they should also be beneficial for children's peer problems because they reduce children's disruptive behavior and may increase prosocial behavior. Crucially, these approaches share a fundamental assumption: that behavior deficits on the part of children with ADHD are the predominant (or exclusive) cause of their peer problems, and that if children remedy their inappropriate behaviors, peers will notice these changes and respond with liking.

Whereas behavioral management $[61 \cdot, 62]$ and medication approaches $[63,64]$ have robust empirical support for ameliorating children's inappropriate behaviors, improvements in peers' liking often fail to follow. For example, the Multimodal Treatment Study of Children with ADHD (MTA) is the most comprehensive intervention study to date in this population. Children received 14 months of intensive behavioral management involving instructing both the parent and the teacher to implement the procedures and regular social skills training lessons, and/or 14 months of intensive medication, as compared to a control group that did not receive treatments provided by study personnel. Despite indication that disruptive behaviors as well as prosocial behaviors had improved (particularly for the children receiving both medication and behavioral management as well as medication alone) [63], children with ADHD did not demonstrate improvements in their peer rejection and friendlessness when assessed via sociometric nominations in their classrooms [65]. As discussed by the authors, it is perplexing that the state-of-the-art treatments, empirically supported for ADHD symptoms and delivered under ideal circumstances, failed to improve peer relationships.

Social skills training is typically therapist-led instruction to children about appropriate social behavior, and is intended to more directly target the behavior deficits thought to be maintaining the peer problems of children with ADHD [66, 67]. However, based on significant studies finding no benefit of intensive social skills training on the peer relationships of children with ADHD [68, 69], three recent major reviews have concluded that this approach is ineffective for ADHD populations, at least as is provided in traditional clinic-based settings $[61 \cdot, 70,71]$.

In sum, existing approaches to improve peer problems in children with ADHD are largely ineffective, in particular when 
the gold standard outcome of sociometric nominations are used. We argue that the poor efficacy of existing interventions for peer problems is a function of their failure to consider the contribution of the peer group (see Fig. 1). That is, existing interventions focus on remediating poor prosocial skills and disruptive behavior within the child with ADHD and ignore the influences of the rejecting peers. However, behavior change in the child with ADHD may be a necessary, but not sufficient, condition to result in peers' acceptance. As such, these interventions may not be maximally efficacious unless they incorporate procedures to address the peer group factors that also contribute to peer impairment for children with ADHD [46].

\section{Examples of Interventions Following the Social Contextual} Model

Below we briefly present two examples of interventions from our work that attempt to address these social contextual factors in the peer group that contribute to peer problems among children with ADHD. The aim of this work is to improve the efficacy of treatments for peer problems in ADHD populations.

Making Socially Accepting Inclusive Classrooms. Making Socially Accepting Inclusive Classrooms (MOSAIC) is a classroom-based intervention in which teachers are instructed to encourage peers to be inclusive and welcoming toward children with ADHD; these teacher practices are meant to address the negative cognitive biases that peers frequently possess toward children with this condition $[72 \bullet, 73]$. As shown in Fig. 1, to address social devaluation, teachers are encouraged to develop genuine, warm, and positive relationships with children with ADHD, as these are thought to set a model for peers to follow. To address exclusionary peer behavior, teachers set (and enforce) clear classroom rules for social inclusion and arrange activities to facilitate the formation of positive social bonds. To address reputational bias, teachers explicitly call attention to genuine strengths of children with ADHD. In addition, to address the behavior deficits of children with ADHD, MOSAIC teachers are also trained to institute classroom behavioral management procedures and social skills training lessons, empirically supported to reduce ADHD symptoms and disruptive behavior [63,74]. This is because the theory behind MOSAIC is that addressing the behavior deficits in children with ADHD is a necessary, but not sufficient condition for increasing peers' liking and dyadic friendship.

In a small randomized pilot study, the efficacy of MOSAIC was tested in a sample of 24 children with ADHD participating in a 2-week summer day camp with 113 typically developing peers. All children were previously unacquainted before the start of camp. The children with ADHD were assigned using a repeated measures crossover design to classrooms where the teacher was trained to deliver either (a) MOSAIC; or (b) the behavioral management and social skills training components of MOSAIC (to improve socially competent behavior in children with ADHD) without the components to increase peers' inclusiveness toward children with ADHD. The aim of this study was to isolate the potential incremental efficacy of components targeting peer group factors on improving children's peer functioning.

Results suggested that children with ADHD were better liked and less disliked by peers, and had more reciprocated friendships, as assessed via sociometric measures, when they were in classrooms where MOSAIC was added to behavioral management and social skills training [72•]. These results were supported by observations of peers behaving more positively toward children with ADHD in classrooms where MOSAIC was present, relative to in the comparison condition [72•]. Notably, the typically developing classmates also showed improved peer sociometric functioning in the MOSAIC condition relative to in the comparison condition, albeit with smaller effect sizes than did the children with ADHD [73].

Parental Friendship Coaching. The Parental Friendship Coaching (PFC) intervention consists of parent groups where instruction is provided about how parents can become "friendship coaches" for their children with ADHD [75]. Unlike typical social skills training interventions, PFC has no child treatment component and instead focuses on training the parents to address peer group factors. Specifically, PFC is predicated on the theory that changing the child's standing within the peer group at large may be challenging (or something that is not feasible for parents to undertake). However, parents play a significant role in helping their children develop close, high quality, dyadic friendships, particularly by arranging one on one playdates for their child with potential friends $[14,76]$. Strengthening their children's dyadic friendships may be a worthwhile pursuit that may ultimately benefit the child with ADHD even if his or her peer rejection in the classroom at large does not change [77].

In PFC (see Fig. 1), parents address social devaluation by networking and building good relationships with other parents, which can help other parents and their children develop more accepting views of the child with ADHD. Parents are instructed to address exclusionary peer behavior and reputational bias by arranging fun, structured playdates where the child with ADHD and the friend (a) need to work together in order to succeed at the task and must involve one another; and (b) are likely to have a fun, positive experience. Importantly, in PFC, as in MOSAIC, parents are also taught ways to address the behavior deficits of children with ADHD through behavioral contingency management and instruction in social skills, and apply these methods to reduce disruptive behavior and increase prosocial behavior during playdates.

A pilot study involved families of 62 children with ADHD, randomly assigned to receive PFC or to be in a no-treatment 
control group. Children whose parents received PFC were reported by parents to show better social behaviors, and were reported by teachers (who were unaware of whether the family was provided the intervention) to be more accepted and less rejected by their peers, relative to children whose parents were in the control group [75]. Observations of warm, non-critical, and instructive parental coaching behaviors were more frequent among parents who had received PFC, and these parental behaviors partially mediated the effect of the intervention on children's peer relationships (as reported by parents and teachers), providing support for the theoretical model of change [75].

Limitations of these Interventions. Despite the findings that children with ADHD demonstrated statistically reliable gains in peer functioning after receiving MOSAIC as well as PFC, there are several limitations to these results. First, in both studies peer functioning of treated children with ADHD remained approximately 1 standard deviation below the peer functioning of typically developing children $[72 \bullet, 75]$. The one exception to this was that for boys with ADHD in MOSAIC, data suggested that the number of reciprocated friendships matched those obtained by the typically developing sample [72•]. Therefore, most children with ADHD remained impaired in their peer relationships after treatment, despite having made gains.

A second limitation of these findings pertains to uncertainty regarding how long intervention effects will persist after the discontinuation of treatment. We note that in general, there are few interventions for ADHD that demonstrate sustained benefits after treatment discontinuation [78], and longer followups of MOSAIC and PFC are needed. Another issue is that only the small pilot study of MOSAIC [72•] compared the study treatment against an active attention control condition to match participants' expectations for improvement. Finally, demonstration of efficacy on sociometric measures of peer regard, in addition to efficacy on measures of social behaviors, is important. Although sociometric measures were included in the trial of MOSAIC, they were not part of PFC. In an attempt to address these gaps in the existing literature, we are currently undertaking a new trial of PFC that contains a longer followup period, an active attention control treatment condition, sociometric outcome measures, and multidimensional assessment of friendship outcomes (e.g., number of friends, friendship quality, behavioral characteristics of friends).

\section{Conclusions}

Peer problems are a persistent and treatment refractory area of impairment for the population of children with ADHD. Currently there is no intervention that normalizes the peer functioning of children with ADHD, even if the intervention is associated with improvement. As such, there remains a clear and persistent need for better interventions for peer problems in this population. Because nearly all existing approaches focus on changing the behavior deficits of children with ADHD, an exciting future direction may be to investigate approaches aimed at helping the typically developing peer group to reduce stigma about ADHD behaviors and enhance acceptability of individual differences [72•, 73]. We propose that interventions that combine approaches targeting the inappropriate behaviors of children with ADHD with approaches to increase the inclusiveness of the peer group may be most likely to normalize social functioning in ADHD populations.

\section{Compliance with Ethics Guidelines}

Conflict of Interest Amori Yee Mikami and Sébastien Normand declare that they have no conflict of interest.

Human and Animal Rights and Informed Consent This article does not contain any studies with human or animal subjects performed by any of the authors.

\section{References}

Papers of particular interest, published recently, have been highlighted as:

- Of importance

1. American Psychiatric Association. Diagnostic and statistical manual of mental disorders. 5th ed. Arlington: American Psychiatric Publishing; 2013.

2. Bagwell CL et al. Attention-deficit hyperactivity disorder and problems in peer relations: predictions from childhood to adolescence. $\mathrm{J}$ Am Acad Child Adolesc Psychiatry. 2001;40(11):1285-92.

3. Hoza B et al. What aspects of peer relationships are impaired in children with attention-deficit/hyperactivity disorder? J Consult Clin Psychol. 2005;73(3):411-23.

4. Dirks MA, Treat TA, Weersing VR. Integrating theoretical, measurement, and intervention models of youth social competence. Clin Psychol Rev. 2007;27(3):327-47.

5. Rubin KH, Bukowski WM, Parker JG. Peer interactions, relationships, and groups. In: Eisenberg N, editor. Handbook of child psychology, Social, emotional, and personality development, vol. 3. Hoboken: John Wiley \& Sons; 2006. p. 571-645.

6. Asarnow JR. Peer status and social competence in child psychiatric inpatients: a comparison of children with depressive, externalizing, and concurrent depressive and externalizing disorders. J Abnorm Child Psychol. 1988;16(2):151-62.

7. Gresham FM et al. Comorbidity of hyperactivity-impulsivityinattention and conduct problems: risk factors in social, attentive, and academic domains. J Abnorm Child Psychol. 1998;26(5):393406.

8. Waschbusch DA. A meta-analytic examination of comorbid hyperactive-impulsive-attention problems and conduct problems. Psychol Bull. 2002;128(1):118-50.

9. Cohen J. Statistical power analysis for the behavioral sciences. 2nd ed. Hillsdale: Lawrence Earlbaum Associates; 1988.

10. Diamantopoulou S, Henricsson L, Rydell A-M. ADHD symptoms and peer relations of children in a community sample: examining 
associated problems, self-perceptions, and gender differences. Int J Behav Dev. 2005;29(5):388-98.

11. Tseng W-L et al. Relations of inattention and hyperactivity/ impulsivity to preadolescent peer functioning: the mediating roles of aggressive and prosocial behaviors. J Clin Child Adolesc Psychol. 2012;41(3):275-87.

12. Andrade BF, Tannock R. Sustained impact of inattention and hyperactivity-impulsivity on peer problems: mediating roles of prosocial skills and conduct problems in a community sample of children. Child Psychiatry Hum Dev. 2014;45(3):318-28.

13. Erhardt D, Hinshaw SP. Initial sociometric impressions of attentiondeficit hyperactivity disorder and comparison boys: predictions from social behaviors and from nonbehavioral variables. J Consult Clin Psychol. 1994;62(4):833-42.

14. Mikami AY et al. Parental influence on children with attentiondeficit/hyperactivity disorder: I. Relationships between parent behaviors and child peer status. J Abnorm Child Psychol. 2010;38(6): 721-36.

15. Hinshaw SP, Melnick SM. Peer relationships in boys with attentiondeficit hyperactivity disorder with and without comorbid aggression. Dev Psychopathol. 1995;7(4):627-47.

16. Pelham WE, Bender ME. Peer relationships in hyperactive children: description and treatment. In: Gadow KD, Bailer I, editors. Advances in learning and behavioral disabilities. Greenwich: JAI Press; 1982. p. 365-436.

17. Mikami AY. The importance of friendship for youth with attentiondeficit/hyperactivity disorder. Clin Child Fam Psychol Rev. 2010;13(2):181-98.

18. Parker JG, Asher SR. Friendship and friendship quality in middle childhood: links with peer group acceptance and feelings of loneliness and social dissatisfaction. Dev Psychol. 1993;29(4):611-21.

19. Blachman DR, Hinshaw SP. Patterns of friendship among girls with and without attention-deficit/hyperactivity disorder. J Abnorm Child Psychol. 2002;30(6):625-40.

20. Normand $\mathrm{S}$ et al. How do children with ADHD (mis)manage their real-life dyadic friendships? A multi-method investigation. J Abnorm Child Psychol. 2011;39(2):293-305.

21. Normand $\mathrm{S}$ et al. Continuities and changes in the friendships of children with and without ADHD: a longitudinal, observational study. J Abnorm Child Psychol. 2013;41(7):1161-75. This study involves observational measures over a 1 year period to characterize the friendship problems among children with ADHD, compared to a matched sample of typically developing children.

22. Marton I et al. Friendship characteristics of children with ADHD. J Atten Disord. doi:10.1177/1087054712458971.

23. Heiman T. An examination of peer relationships of children with and without attention deficit hyperactivity disorder. Sch Psychol Int. 2005;26(3):330-9.

24. Mikami AY, Hinshaw SP. Resilient adolescent adjustment among girls: buffers of childhood peer rejection and attention-deficit/hyperactivity disorder. J Abnorm Child Psychol. 2006;34(6):823-37.

25. Greene RW et al. Adolescent outcome of boys with attentiondeficit/hyperactivity disorder and social disability: results from a 4-year longitudinal follow-up study. J Consult Clin Psychol. 1997;65(5):758-67.

26. Mikami AY et al. Eating pathology among adolescent girls with attention-deficit/hyperactivity disorder. J Abnorm Psychol. 2008;117(1):225-35.

27. Tseng W-L et al. Symptoms of attention-deficit/hyperactivity disorder and peer functioning: a transactional model of development. J Abnorm Child Psychol. 2014;42(8):1353-65. This article highlights the transactional relationships between ADHD symptoms and peer problems, demonstrating how peer difficulties may also predict increased inattention and hyperactivity/impulsivity over time.
28. Murray-Close D et al. Developmental processes in peer problems of children with attention-deficit/hyperactivity disorder in the Multimodal Treatment Study of Children with ADHD: developmental cascades and vicious cycles. Dev Psychopathol. 2010;22(4): 785-802.

29. Ladd GW, Herald-Brown SL, Reiser M. Does chronic classroom peer rejection predict the development of children's classroom participation during the grade school years? Child Dev. 2008;79(4):1001-15.

30. Reuland MM, Mikami AY. Classroom victimization: consequences for social and academic adjustment in elementary school. Psychol Sch. 2014;51(6):591-607.

31. Boivin M, Hymel S, Burkowski WM. The roles of social withdrawal, peer rejection, and victimization by peers in predicting loneliness and depressed mood in childhood. Dev Psychopathol. 1995;7(4):765-85.

32. Lee SS, Hinshaw SP. Severity of adolescent delinquency among boys with and without attention deficit hyperactivity disorder: predictions from early antisocial behavior and peer status. J Clin Child Adolesc Psychol. 2004;33(4):705-16.

33. Ladd GW. Having friends, keeping friends, making friends, and being liked by peers in the classroom: predictors of children's early school adjustment? Child Dev. 1990;61(4): 1081-100.

34. Bagwell CL, Newcomb AF, Bukowski WM. Preadolescent friendship and peer rejection as predictors of adult adjustment. Child Dev. 1998;69(1):140-53.

35. Bagwell CL et al. Friendship and peer rejection as predictors of adult adjustment. In: Nangle D, Erdley C, editors. The role of friendship in psychological adjustment. New directions for child and adolescent development. San Francisco: Jossey-Bass Inc; 2001. p. 25-49.

36. Cardoos SL, Hinshaw SP. Friendship as protection from peer victimization for girls with and without ADHD. J Abnorm Child Psychol. 2011;39(7):1035-45.

37. Mrug $\mathrm{S}$ et al. Peer rejection and friendships in children with attention-deficit/hyperactivity disorder: contributions to long-term outcomes. J Abnorm Child Psychol. 2012;40(6):1013-26.

38. Rosen PJ et al. Social self-control, externalizing behavior, and peer liking among children with ADHD-CT: a mediation model. Soc Dev. 2014;23(2):288-305.

39. Maedgen JW, Carlson CL. Social functioning and emotional regulation in the attention deficit hyperactivity disorder subtypes. J Clin Child Psychol. 2000;29(1):30-42.

40. Mrug $\mathrm{S}$ et al. Behavior and peer status in children with ADHD: continuity and change. J Atten Disord. 2007;10(4):359-71.

41. Marton I et al. Empathy and social perspective taking in children with attention-deficit/hyperactivity disorder. J Abnorm Child Psychol. 2009;37(1):107-18.

42. Melnick SM, Hinshaw SP. What they want and what they get: the social goals of boys with ADHD and comparison boys. J Abnorm Child Psychol. 1996;24(2):169-85.

43. Sibley MH, Evans SW, Serpell ZN. Social cognition and interpersonal impairment in young adolescents with ADHD. J Psychopathol Behav Assess. 2010;32(2):193-202.

44. Mikami AY et al. Relationships between social information processing and aggression among adolescent girls with and without ADHD. J Youth Adolesc. 2008;37(7):761-71.

45. Mikami AY, Calhoun CD, Abikoff HB. Positive illusory bias and response to behavioral treatment among children with attentiondeficit/hyperactivity disorder. J Clin Child Adolesc Psychol. 2010;39(3):373-85.

46. Mikami AY, Lerner MD, Lun J. Social context influences on children's rejection by their peers. Child Dev Perspect. 2010;4(2): $123-30$. 
47. Wright JC, Giammarino M, Parad HW. Social status in small groups: individual-group similarity and the social "misfit.". J Pers Soc Psychol. 1986;50(3):523-36.

48. Stormshak EA et al. The relation between behavior problems and peer preference in different classroom contexts. Child Dev. 1999;70(1):169-82.

49. Jackson MF et al. Classroom contextual effects of race on children's peer nominations. Child Dev. 2006;77(5):1325-37.

50. Hinshaw SP. The stigmatization of mental illness in children and parents: developmental issues, family concerns, and research needs. J Child Psychol Psychiatry. 2005;46(7):714-34.

51. Juvonen J. Deviance, perceived responsibility, and negative peer reactions. Dev Psychol. 1991;27(4):672-81.

52. Canu WH et al. Social appraisal of adult ADHD: stigma and influences of the beholder's big five personality traits. J Atten Disord. 2008;11(6):700-10

53. Whalen CK et al. Child and adolescent perceptions of normal and atypical peers. Child Dev. 1983;54(6):1588-98.

54. Asher SR, Rose AJ, Gabriel SW. Peer rejection in everyday life. In: Leary MR, editor. Interpersonal rejection. New York: Oxford University Press; 2001. p. 105-42.

55. Perry DG, Kusel SJ, Perry LC. Victims of peer aggression. Dev Psychol. 1988;24(6):807-14.

56. Harris MJ et al. Self-fulfilling effects of stigmatizing information on children's social interactions. J Pers Soc Psychol. 1992;63(1):4150 .

57. Harris MJ, Milich R, McAninch CB. When stigma becomes selffulfilling prophecy: expectency effects and the causes, consequences, and treatment of peer rejection. In: Brophy J, editor. Advances in research on teaching. Greenwich: JAI Press; 1998. p. 243-72.

58. Hymel S, Wagner E, Butler LJ. Reputational bias: view from the peer group. In: Asher SR, Coie JD, editors. Peer rejection in childhood. New York: Cambridge University Press; 1990. p. 156-86.

59. Peets K, Hodges EVE, Salmivalli C. Affect-congruent social-cognitive evaluations and behaviors. Child Dev. 2008;79(1):170-85.

60. Peets $\mathrm{K}$ et al. Hostile attributions and behavioral strategies in children: does relationship type matter? Dev Psychol. 2007;43(4):889-900.

61. Evans SW, Owens JS, Bunford N. Evidence-based psychosocial treatments for children and adolescents with attention-deficit/hyperactivity disorder. J Clin Child Adolesc Psychol. 2014;43(4):527-51. This review paper summarizes the literature on evidence based psychosocial interventions for youth with $A D H D$, highlighting the limitations of existing interventions for peer impairment.

62. Fabiano GA et al. A meta-analysis of behavioral treatments for attention-deficit/hyperactivity disorder. Clin Psychol Rev. 2009;29(2):129-40.

63. MTA Cooperative Group. A 14-month randomized clinical trial of treatment strategies for attention-deficit/hyperactivity disorder. Arch Gen Psychiatry. 1999;56(12):1073-86.

64. Abikoff HB et al. Symptomatic improvement in children with ADHD treated with long-term methylphenidate and multimodal psychosocial treatment. J Am Acad Child Adolesc Psychiatry. 2004;43(7):802-11.

65. Hoza B et al. Peer-assessed outcomes in the multimodal treatment study of children with attention deficit hyperactivity disorder. J Clin Child Adolesc Psychol. 2005;34(1):74-86.

66. Nixon E. The social competence of children with attention deficit hyperactivity disorder: a review of the literature. Child Psychol Psychiatr Rev. 2001;6:172-80.

67. Stormont M. Social outcomes of children with AD/HD: contributing factors and implications for practice. Psychol Sch. 2001;38: 521-31.

68. Abikoff HB et al. Social functioning in children with ADHD treated with long-term methylphenidate and multimodal psychosocial treatment. J Am Acad Child Adolesc Psychiatry. 2004;43(7):820 9.

69. Antshel KM, Remer R. Social skills training in children with attention deficit hyperactivity disorder: a randomized-controlled clinical trial. J Clin Child Adolesc Psychol. 2003;32(1):153-65.

70. Pelham WE, Fabiano GA. Evidence-based psychosocial treatments for attention-deficit/hyperactivity disorder. J Clin Child Adolesc Psychol. 2008;37(1):184-214.

71. Storebø OJ et al. Social skills training for Attention Deficit Hyperactivity Disorder (ADHD) in children aged 5 to 18 years. Cochrane Database Syst Rev. 2011;(12). doi:10.1002/14651858. CD008223.pub2.

72. Mikami AY et al. A randomized trial of a classroom intervention to increase peers' social inclusion of children with attention-deficit/hyperactivity disorder. J Consult Clin Psychol. 2013;81(1):100-12. This article reports efficacy data from a novel intervention that considers, and attempts to address, the social contextual factors that affect peer problems among children with ADHD.

73. Mikami AY et al. Collateral effects of a peer relationship intervention for children with ADHD on typically developing classmates. Sch Psychol Rev. 2013;42(4):458-76.

74. Epstein M, Cullinan D, Kutash K, Weaver R. In: U.S. Department of Education National Center for Education Statistics, editor. Reducing behavior problems in the elementary school classroom. IES Practice Guide. (NCEE 2008-012). Washington: U.S. Government Printing Office; 2008.

75. Mikami AY et al. Parental influence on children with attentiondeficit/hyperactivity disorder: II. Results of a pilot intervention training parents as friendship coaches for children. J Abnorm Child Psychol. 2010;38(6):737-49.

76. Frankel F, Mintz J. Maternal reports of play dates of clinic referred and community children. J Child Fam Stud. 2011;20(5):623-30.

77. Hoza B et al. A friendship intervention for children with attentiondeficit/hyperactivity disorder: preliminary findings. J Atten Disord. 2003;6(3):87-98.

78. Molina BSG et al. The MTA at 8 years: prospective follow-up of children treated for combined-type ADHD in a multisite study. J Am Acad Child Adolesc Psychiatry. 2009;48(5):484-500. 